\title{
KEANEKARAGAMAN TUMBUHAN HERBA DAN PERDU PADA JALUR PENDAKIAN LEMBAH RAMMA DI GUNUNG BAWAKARAENG KABUPATEN GOWA
}

\section{DIVERSITY OF HERBS AND SHRUBS ON RAMMA TRACK IN MOUNT BAWAKARAENG, GOWA DISTRICT}

\author{
Musyawir $^{1}$, Andi Nur Samsi ${ }^{*}$, Ahmad Hasyim ${ }^{3}$ \\ ${ }^{1}$ Mahasiswa Program Studi Pendidikan Biologi STKIP Pembangunan Indonesia, Makassar, Indonesia \\ ${ }^{2,3}$ Program Studi Pendidikan Biologi STKIP Pembangunan Indonesia, Makassar, Indonesia \\ *Email: andinursamsi89@gmail.com
}

Diterima: 29 Januari 2021. Disetujui: 13 Maret 2021. Dipublikasikan: 22 April 2021

\begin{abstract}
Abstrak: Penelitian ini bertujuan mengetahui jenis dan keanekaragaman tumbuhan penutup (herba dan perdu) yang terdapat pada jalur pendakian Lembah Ramma di Gunung Bawakaraeng Kabupaten Gowa. Penelitian ini di laksanakan pada bulan Juli-September 2018 pada jalur pendakian lembah Ramma di Gunung Bawakaraeng Kabupaten Gowa pada bulan Juli sampai September 2018. Jenis penelitian yang digunakan bersifat deskriptif kuantitatif. Pengamatan mengunakan transek, di buat 20 plot yang berukuran 2x2 meter. Sampel spesies yang ada dalam plot diambil kemudian difoto dan diidentifikasi. Hasil penelitian ditemukan 24 spesies terdiri dari 19 tumbuhan herba dan 5 tumbuhan perdu. Indeks keanekaragaman ( $\left.\mathrm{H}^{\prime}\right)$ tumbuhan herba adalah adalah 2,451 termasuk sedang, untuk tumbuhan perdu adalah 1,379 termasuk rendah. Keanekaragaman tumbuhan herba tergolong sedang dan tumbuhan perdu tergolong rendah pada jalur pendakian Lembah Ramma di Gunung Bawakaraeng Kabupaten Gowa.
\end{abstract}

Kata Kunci : Keanekaragaman, Tumbuhan Penutup, Lembah Ramma, Gunung Bawakaraeng

Abstract: This study aims to determine the types and diversity of cover plants (herbs and shrubs) found in the Ramma Valley climbing route on Mount Bawakaraeng, Gowa Regency. This research was conducted in JulySeptember 2018 on the track of the Ramma valley on Mount Bawakaraeng, Gowa Regency from July to September 2018. The type of research used is descriptive quantitative. Observation using transects made 20 plots measuring $2 \times 2$ meters. Species samples in the plot were taken and then photographed and identified. The research found 24 species consisting of 19 herbs and 5 shrubs. The diversity index $\left(\mathrm{H}^{\prime}\right)$ of herb plants is 2.451 which is moderate, for shrubs it is 1.379 which is low. Diversity of herbs are moderate and low shrubs on the Ramma Valley hiking trail on Mount Bawakaraeng, Gowa Regency.

Keywords : Diversity, Cover Plants, Ramma Valley, Bawakaraeng Mount

\section{PENDAHULUAN}

Tumbuhan penutup dalam hutan sangat beranekaragam jenisnya. Tumbuhan penutup yang dimaksud dalam penelitian ini adalah tumbuhan yang terdiri dari tumbuhan selain pohon, contohnya rumput, herba, dan semak belukar atau biasa disebut perdu, serta paku-pakuan [1].

Tumbuhan penutup juga mempunyai peran yang penting yaitu salah satunya sebagai bahan makanan pangan [2]. Tumbuhan penutup tanah sangat berperan dalam menjaga keseimbangan ekosistem [3]. Kelompok tumbuhan penutup yang diteliti yaitu tumbuhan herba dan perdu. Salah satu lokasi yang cocok untuk melakukan penelitian tumbuhan herba dan perdu yaitu di Gunung Bawakaraeng.

Gunung Bawakaraeng merupakan salah satu gunung tertinggi di Sulawesi Selatan dengan ketinggian $2.845 \mathrm{~m}$ di atas permukaan laut. Hutan Gunung Bawakaraeng dikenal secara lokal, nasional, maupun internasional sebagai kawasan ekowisata yang banyak dikunjungi oleh pencinta alam. Gunung ini terletak di Kawasan Malino Kabupaten Gowa dan masih memiliki vegetasi yang bagus. Masyarakat sekitar memanfaatkan keindahan alam gunung ini sebagai tempat wisata dan tanah di kaki gunung sebagai lahan lahan pertanian.

Kawasan hutan gunung Bawakaraeng merupakan salah satu hutan pegunungan tropis di Indonesia yang memiliki keanekaragaman pohon yang tinggi termasuk tumbuhan Penutup. Jenis-jenis dari suku Araceae dan paku-pakuan sangat banyak dijumpai. Namun demikian, adanya jalan masuk menuju puncak yang sering dilalui orang dapat menjadi ancaman bagi kelestarian dan berkurangnya keragaman vegetasi tumbuhan penutup hutan gunung Bawakaraeng khususnya di Jalur Pendakian ke Lembah Ramma.

Berdasarkan uraian di atas, perlu di lakukan penelitian tentang Keanekaragaman Tumbuhan Penutup pada Jalur Pendakian Lembah Ramma di Gunung Bawakaraeng Kabupaten Gowa.. Karena sejauh ini belum di peroleh informasi atau data awal tentang susunan dan bentuk tumbuhan penutup yang ada pada Jalur Pendakian Lembah Ramma di Gunung Bawakaraeng. 


\section{METODE PENELITIAN}

Penelitian ini dilaksanakan di Kawasan Hutan gunung Bawakaraeng jalur pendakian Lembah Ramma Kabupaten Gowa. Penelitian ini akan di lakukan pada bulan Juli sampai September 2018. Titik koordinat lokasi penelitian yaitu $5^{\circ} 17^{\prime} 46,101$ 'S dan $119^{\circ} 54^{\prime} 55,492^{\prime \prime} \mathrm{E}$

Penentuan titik sampling dilakukan secara purposive sampling yaitu lokasi Stasiun ditentukan secara sengaja berdasarkan pertimbangan jenis tumbuhan Penutup yang ada di Kawasan hutan gunung Bawakaraeng sepanjang jalur pendakian ke Lembah Ramma. Alasan menggunakan teknik purposive sampling karena jenis tumbuhan penutup pada stasiun penelitian tidak tersebar secara merata, sehingga penentuan titik sampling dapat dilakukan secara sengaja.

Bentuk desain sampel yang digunakan untuk mengetahui jenis tumbuhan penutup yang berada di kawasan hutan Gunung Bawakaraeng sepanjang jalur pendakian ke Lembah Ramma adalah pada tiap lokasi penelitian dibuat 4 transek mulai dari stasiun 1 , stasiun 2, stasiun 3, stasiun 4, jarak antara transek yaitu 600 meter hingga $1 \mathrm{~km}$. Penentuan desain petak contoh menggunakan metode garis berpetak. Masingmasing petak contoh berukuran $2 \times 2$ meter Tiap transek terdiri 5 petak, dengan jarak antar petak sekitar 100 meter diharapkan mewakili tiap jenis tumbuhan penutup [4].

Identifikasi jenis dapat dilakukan menggunakan buku literatur tentang tumbuhan penutup yang diantaranya yaitu buku Flora [5] dan buku Taksonomi Tumbuhan (Spermatophyta) [6]. Untuk menentukan besarnya keragaman jenis tumbuhan dilakukan analisis dengan menggunakan Indeks Shannon-Wiener dalam [4] sebagai berikut:

$\mathrm{H}^{\prime}=-\Sigma\left\{\left(\frac{\mathrm{n}_{\mathrm{i}}}{\mathrm{N}}\right) \ln \left(\frac{\mathrm{n}_{\mathrm{i}}}{\mathrm{N}}\right)\right\}$

dengan:

$\mathrm{H}^{\prime}=$ indeks keanekaragaman Shannon-Wiener

n.i = Jumlah individu jenis

$\mathrm{N}=$ total jumlah individu

Nilai derajat keanekaragaman (H') suatu komunitas biasanya lebih besar dari nol. Apabila derajat keanekaragaman:

$\left(\mathrm{H}^{\prime}\right)<1$ maka keanekaragamanya rendah,

$1 \leq \mathrm{H}^{\prime} \geq 3$ keanekaragamannya sedang, dan

$\mathrm{H}^{e e}>3$ maka keanekaragamannya tinggi.

\section{HASIL DAN PEMBAHASAN}

\section{Spesies Tumbuhan Penutup yang ditemukan}

Hasil pengamatan di sepanjang jalur pendakian lembah Ramma Gunung Bawakaraeng diperoleh 24 spesies yang terdiri dari 19 spesies tumbuhan herba, dan 5 spesies tumbuhan perdu (Tabel 1).

\section{Tumbuhan Herba}

Tumbuhan herba yang ditemukan di sepanjang jalur pendakian lembah Ramma Gunung Bawakaraeng yaitu terdiri dari 12 famili, 19 genus dan 19 spesies. Pengamatan dilakukan dengan membuwat plot berukuran $2 \times 2$ meter. Pemasangan plot dilakukan dengan acak berjumlah 20 plot, mencari kawasan yang cahaya matahari dapat masuk kedalam hutan sehingga memungkinkan terdapat tumbuhan bawah yang tumbuh.kedalam hutan sehingga memungkinkan terdapat tumbuhan bawah yang tumbuh.

Banyaknya jenis tumbuhan herba yang ditemukan di sepanjang jalur pendakian lembah Ramma Gunung Bawakaraeng disebabkan karna banyak faktor yang mendukung seperti suhu, kelembapan, Intensitas cahaya dan $\mathrm{pH}$ tanah. Meskipun demikian tumbuhan juga memiliki cara sendiri untuk mempertahankan populasi jenisnya dari gangguan organisme lain.

Pada KHDTK Kaliurang Yogyakarta ditemukan 27 jenis herba dari 11 famili [7]. Hasil yang jauh lebih banyak dibandingkan dengan hasil penelitian yang diperoleh. Selain itu, di DAS Tapak Moge ditemukan hasil yang jauh lebih banyak yaitu 48 spesies dari 23 famili [8]. Pada di Cagar Alam Sibolangit temukan herba jauh lebih banyak yaitu 87 jenis dan 44 famili. Perbedaan mencolok ini disebabkan perbedaan kelembaban dengan intensitas cahaya yang tinggi dan tempat yang relatif terbuka serta tiupan angin yang sangat baik untuk pertumbuhan dan perkembangan tumbuhan herba di Cagar Alam Sibolangit [9].

\section{Tumbuhan Perdu}

Tumbuhan perdu yang ditemukan di sepanjang jalur pendakian lembah Ramma Gunung Bawakaraeng yaitu terdiri dari 4 famili, 5 genus dan 5 spesies. Pengamatan dilakukan dengan membuwat plot berukuran $2 \times 2$ meter. Pemasangan plot dilakukan dengan acak dan berjumlah 20 plot. Jumlah spesies tumbuhan perdu yang ditemukan di sepanjang jalur pendakian lembah Ramma Gunung Bawakaraeng lebih rendah dibandingkan dengan tumbuhan herba. 
Tabel 1. Jenis tumbuhan herba dan perdu yang ditemukan di jalur pendakian Lembah Ramma Gunung Bawakaraeng

\begin{tabular}{|c|c|c|c|c|}
\hline No & Famili & Genus & Nama Ilmiah & Nama Indonesia \\
\hline
\end{tabular}

Tumbuhan Herba

\begin{tabular}{cllll}
\hline 1 & Amaranthaceae & Cyathula & Cyathula prostrate & Pakis Tiang \\
\hline 2 & Apiaceae & Centella & Centella asiatica & Pegagan \\
\hline 3 & Asteraceae & Synedrella & Synedrella nodiflora & Jotang Kuda \\
\hline 4 & Asteraceae & Eclipta & Eclipta prostrate & Urang-Aring \\
\hline 5 & Zingiberaceae & Zingiber & Zingiber zerumbet & Lampuyang \\
\hline 6 & Araceae & Amorphophallus & Amorphophallus variabilis & Kembang Bangkai \\
\hline 7 & Asteraceae & Ageratum & Ageratum conyzoides & Bandotan \\
\hline 8 & Lamiaceae & Hyptis & Hyptis capitates & Hiptis \\
\hline 9 & Asteraceae & Emilia & Emilia sonchifolia & Temu wiyang \\
\hline 10 & Rubiaceae & Spermacoce & Spermacoce remota & Kremah \\
\hline 11 & Urticaceae & Laportea & Laportea interrupta & Jelatan \\
\hline 12 & Amaranthaceae & Amaranthus & Amaranthus spinosus & Bayam duri \\
\hline 13 & Lamiaceae & Leucas & Leucas lavandulifolia & Lenglengan \\
\hline 14 & Fabaceae & Mimosa & Mimosa pudica & Putri Malu \\
\hline 15 & Dryopteridaceae & Nephrolepis & Nephrolepis cordifolia & Paku Pedang \\
\hline 16 & Dennstaedtiaceae & Microlepia & Microlepia speluncae & Microlepia \\
\hline 17 & Piperaceae & Peperomia & Peperomia pellucid & Suruhan \\
\hline 18 & Dryopteridaceae & Gymnocarpium & Gymnocarpium Dryopteris & Paku sejati \\
\hline 19 & Lamiaceae & Salvia & Salvia riparia & Trengia \\
\hline
\end{tabular}

Tumbuhan Perdu

\begin{tabular}{lllll}
\hline 1 & Malvaceae & Sida & Sida rhombifolia & Sidaguri \\
\hline 2 & Verbeneaceae & Lantana & Lantana camara & Tembelekan \\
\hline 3 & Verbeneaceae & Stachytarpheta & Stachytarpheta jamaicensis & Pecut Kuda \\
\hline 4 & Moraceae & Ficus & Ficus melanocarpa & Ficus \\
\hline 5 & Asteraceae & Chromalaena & Chromalaena odorata & Krinyuh \\
\hline
\end{tabular}

Faktor yang menyebabkan rendahnya jenis perdu yang ditemukan di sepanjang jalur pendakian lembah Ramma Gunung Bawakaraeng bisa karna faktor lingkungan, gangguan dari tumbuhan atau organisme lain. Gangguan ini bisa diartikan kejadian yang dapat merusak struktur komunitas dan mengubah ketersediaan sumberdaya atau lingkungan fisiknya. Gangguan ini dapat berupa perubahan iklim, gangguan dari manusia atau faktor yang lainnya. Keberadaan tumbuhan invasif juga akan mempengaruhi tumbuhan penutup khususnya tumbuhan lokal [10].

\section{Indeks Kenanekaragaman Tumbuhan Penutup}

Indeks keanekaragaman digunakan untuk mengetahui keanekaragaman hayati yang diteliti. Pada prinsipnya, nilai indeks makin tinggi, berarti komunitas itu makin beragam dan tidak didominasi oleh satu atau lebih dari jenis yang ada.
Indeks keanekaragaman merupakan parameter vegetasi yang sangat berguna untuk membandingkan berbagai komunitas tumbuhan, terutama untuk mempelajari pengaruh gangguan faktor-faktor lingkungan atau abiotik terhadap komunitas atau untuk mengetahui keadaan suksesi atau stabilitas komunitas [11]. Faktor ketinggian, iklim, dan mineral juga mempengaruhi tumbuhan penutup [3], [12].

Besarnya kerapatan jenis, banyaknya jumlah jenis, dan tingkat penyebaran masingmasing jenis tumbuhan juga dapat mempengaruhi kenanekaragaman jenis suatu komunitas [13].

\section{Tumbuhan Herba}

Hasil perhitungan indeks keanekaragaman tumbuhan di sepanjang jalur pendakian lembah Ramma Gunung Bawakaraeng maka dapat diketahui indeks keanekaragamannya adalah 2,451 . Dilihat dari nilainya menunjukan bahwa keanekaragaman tumbuhan herba tergolong sedang. Banyak pepohonan yang tumbuh subur dengan naungan lebat sehingga cahaya matahari 
yang masuk kedalam hutan tidak begitu banyak .Meskipun demikian tumbuhan herba ini tumbuh menyebar hampir menyeluruh,baik di tengah ataupun di tepian hutan.

Penyebaran yang menyeluruh menjadikan mampu mempertahankan keanekaragamannya meskipun dalam jumlah individu yang sedikit. Keberhasilan tumbuhan untuk tumbuh dan bertambah banyak tidaklepas dari daya mempertahankan diri pada kondisi lingkungan [4].

Bukaan hutan dengan intensitas cahaya matahari yang cukup adalah tempat favorit tumbuhan untuk tumbuh dan berkembang karena cahaya matahari sangat berperan penting terhadap kelangsungan hidup tumbuhan penutup khususnya tumbuhan herba untuk proses fotosintesis.

Keanekaragaman tumbuhan herba yang rendah di KHDTK Kaliurang karena hutan tersebut merupakan hutan penelitian dan telah menjadi lokasi penanaman jenis-jenis tanaman introduksi dataran tinggi dalam rangka uji kesesuaian lahan serta lokasi ini pernah terjadi kerusakan akibat letusan gunung tahun 2010 [7]. Kondisi abiotik setiap area bisa bervariasi.

Tumbuhan herba sangat berpotensi sebagai tanaman obat-obatan. Informasi dan pengetahuan yang terbatas mengenai potensi tumbuhan herba membuat pemanfaatannya belum maksimal. Selain itu, tumbuhan herba juga berperan dalam ekosistem hutan [7]. Selain itu, pada DAS Tapak Moge juga ditemukan hasil keanekaragaman tumbuhan herba yang tergolong sedang [8].

\section{Tumbuhan Perdu}

Hasil perhitungan indeks keanekaragaman tumbuhan perdu disepanjang jalur pendakian lembah Ramma Gunung Bawakaraeng maka dapat diketahui indekskeanekaragamannya adalah 1,379. Dilihat dari nilainya menunjukan bahwakeanekaragaman tumbuhan perdu tergolong rendah.

Jumlah jenis tumbuhan bawah dipengaruhi oleh suhu, kelembaban, intensitas cahaya matahari, $\mathrm{pH}$ tanah, kompetisi, dan bencana alam. Tegakan yang rapat akan menyebabkan jenis tumbuhan yang ada di bawahnya ternaungi [2]. Selain itu, iklim mikro juga akan mempengaruhi tumbuhan penutup. Iklim mikro akan membentuk mikrohabitat yang berbedabeda [9].

Keanekaragaman tumbuhan penutup yang sedang juga ditemukan di Cagar Alam Manggis Gadungan. Keanekaragaman tumbuhan penutup juga dipengaruhi oleh cuaca [2].

Sekitar 20 plot disebar acak ke seluruh area jalur pendakian lembah Ramma Gunung Bawakaraeng. Hal ini dilakukan agar mendapatkan sampel berbagai jenis tumbuhan penutup secara keseluruhan. Sulitnya jalan di sepanjang jalur pendakian lembah Ramma Gunung Bawakaraeng merupakan tantangan tersendiri mengingat area tersebut sangat terjal.

Penyebaran yang tidak merata mengakibatkan keanekaragaman tumbuhan perdu ini rendah. Keseluruhan dari 5 spesies tumbuhan perdu yang berhasil diidentifikasi ditemukan di bagian tepi hutan Gunung Bawakaraeng. Keanekaragaman jenis juga dipengaruhi oleh pembagian penyebaran individu dalam tiap jenisnya, tetapi bila penyebaran individu tidak merata maka keanekaragaman jenis dinilai rendah [14].

\section{KESIMPULAN}

1. Tumbuhan penutup Tumbuhan penutup yang di temukan di sepanjang jalur pendakian lembah Ramma Gunung Bawakaraeng terdiri dari 16 famili dan 24 spesies yang terdiri dari 19 tumbuhan herba dan 5 tumbuhan perdu antara lain: Cyathula prostrata, Centella asiatica, Synedrella nodiflora, Eclipta prostrata,Zingiber zerumbet, Amorphophallus variabilis, Ageratum conyzoides, Hyptis capitate, Emilia sonchifolia, Spermacoce remota, Laportea interrupta, Amaranthus spinosus, Leucas lavandulifolia, Mimosa pudica, Nephrolepis cordifolia, Microlepia speluncae, Peperomia pellucida, Gymnocarpium Dryopteris, Salvia riparia, Sida rhombifolia, Lantana camara,Stachytarpheta jamaicensis, Ficus melanocarpa, dan Chromalaena odorata.

2. Indeks keanekaragaman (H') tumbuhan herba adalah 2,451 termasuk sedang, untuk tumbuhan perdu adalah 1,379 termasuk rendah

\section{DAFTAR PUSTAKA}

[1] Abrori, M. (2016). Keanekaragam Tumbuhan Bawah di Cagar Alam Manggis Gadungan Kecamatan Puncu Kabupaten Kediri. UIN Maulana Malik Ibrahim.

[2] Ewusie, J. Y. (1990). Pengantar Ekologi Tropika. Penerjemah Usman Tanuwijaya. Bandung: Penerbit ITB.

[3] Fachrul, M. F. (2007). Metode Sampling Bioteknologi. Jakarta: Bumi Aksara.

[4] Handayani, T., \& Amanah, N. (2018). Keanekaragaman Jenis Tumbuhan Strata Herba di Kawasan Gunung Tidar Kota Magelang sebagai Sumber Belajar Biologi. In SENDIKA: Seminar Nasional Pendidikan FKIP UAD (Vol. 2, pp. 85-90).

[5] Hutasuhut, M. A. (2018). Keanekaragaman Tumbuhan Herba di Cagar Alam Sibolangit. KLOROFIL, 1(2), 69-77.

[6] Indriyanto. (2006). Ekologi Hutan (Cetakan Pe). Jakarta: PT. Bumi Aksara.

[7] Maryani, S., Yusra, Taib, E. N., \& Hidayat, M. (2018). Keanekaragaman Tumbuhan Herba di Daerah Aliran Sungai Tapak moge sebagai Referensi Pendukung Pembelajaran 
Keanekaragaman Hayati di SMAN 16 Takengon. In Prosiding Seminar Nasional Biotik 2018 (pp. 467-473).

[8] Nurmawati, \& Triastinurmiatiningsih, S. (2013). Keanekaragaman Tumbuhan Penutup Tanah Di Taman Nasional Gunung Gede Pangrango, Situgunung, Cisaat, Sukabumi. Retrieved from http://repository.ut.ac.id/id/eprint/5572

[9] Odum, E. P. (1993). Dasar-Dasar Ekologi. Edisi Ketiga (Ketiga). Yogyakarta: Gadjah Mada University Press.

[10] Steenis, C. G. G. J. V. (2008). Flora. Jakarta: PT Pradya Paramita.

[11] Sumroh, D., Wiryono, \& Edi, S. (2018). Keanekaragaman Jenis Tumbuhan Penutup Tanah di Lahan Terbuka Hutan Lindung Bukit Daun Desa Air Lanang Kabupaten Rejang Lebong. Universitas Bengkulu. Retrieved from http://repository.unib.ac.id/id/eprint/18353

[12] Tjitrosoepomo, G. (2010). Taksonomi Tumbuhan (Spermatophyta). Yogyakarta: Gadjah Mada University Press.

[13] Utami, S., \& Baskoro, K. (2017). Struktur Vegetasi Tumbuhan Penutup Tanah di Hutan Wisata Nglimut Gonoharjo Kabupaten Kendal Jawa Tengah. In Prosiding Seminar Nasional MIPA 2017 (pp. 197-201).

[14] Yuskianti, V., Saadi, M. H., \& Handayani, T. (2019). Kenanekaragaman dan Potensi Vegetasi Herba di Kawasan Hutan dengan Tujuan Khusus (KHDTK) Kaliurang Yogyakarta sebagai Obat-Obatan. Jurnal WASIAN, 6(1), 11-26. https://doi.org/10.20886/jwas.v6i1.5057 